\title{
Design and Implementation of Solar Tree
}

\author{
Rishi Sikka
}

\begin{abstract}
The paper is related to the solar energy power generation, more specifically the paper revolves around the topic of solar tree. This paper shows how efficient and important is the solar tree for this generation. This presents how solar trees converts the solar energy into electrical energy. Sunlight irradiates daily and blasts out an enormous amount of solar energy towards the earth, the total energy that is received from the sun is more than enough for humanity to run for many years, still the received solar energy is not harnessed properly and hence there is not sufficient energy production in the world. Since solar panels are the efficient method nowadays for generating electrical energy from the solar energy, but solar panels requires lot of space to install. Hence this paper solve this problem by using solar tree that is mounting of solar panels on artificial tree..
\end{abstract}

Keywords—solar tree, solar panels, PV panels, battery pack.

\section{INTRODUCTION}

The main objective of this paper is to design and implement a solar tree. This paper finds every aspect of the solar tree to work efficiently than other conventional methods of harnessing solar energy by solar panels.

The solar tree will provide electrical energy in areas where electrical grid is not reached yet, and hence can lighten up many homes with affordable price. The renewable energy sources generates electrical energy efficiently without any impact on the environment [1][2].

The idea of the solar tree [3][4] is a new method for installing the solar panels in various angles and position on a tree like structure thus saving a huge amount of space when installing it by conventional method. The tree made is like real life tree that consists stem, multiple branches and solar panels as leaves. The main pole consists all the electronics components and then multiple branches grows out of the tree, on that branches multiple solar panels are mounted for harnessing maximum solar energy. The solar panels are mounted in such a way that each solar panel gets maximum solar irradiation from the sun and generates maximum power output. The solar tree will only take $1 \%$ of the area in comparison with the land that is required by the conventional installation of the PV panels. Since price of land is increasing day by day in almost every country the solar tree will drop down the installation price of the PV panels in comparison with the land.

The usable land that can be used as a cultivating field is going to be more costly than in the coming future. There are many ongoing projects that are undertaken by the government and are facing many issues regarding the acquisition of the land. Hence there is a need for a device or a method or a system for providing efficient and maximum power from a defined space of area, without utilizing much area generating economical revenue.

Revised Manuscript Received on August 05, 2019.

Rishi Sikka, Department of Electronics Engineering, Sanskriti University, Uttar Pradesh, India. (E-mail: sanpubip@gmail.com)

\section{THE SOLAR ENERGY}

The solar energy emitted by our star i.e. sun is in unimaginably huge amount, the total energy generation from the sun within three minutes is more than sufficient for humanity to consume this energy throughout the year [5]. The sun's solar energy can be harvested in many different ways, there is no limit for harvesting the solar energy and then using it for further use.

The one way or method is harvesting solar irradiation by means of photovoltaic cells. In photovoltaic cells multiple semiconductors captures the solar irradiation that are called solar cells, and these solar cells then convert the solar irradiation into electrical energy [6]. When the solar irradiation falls on the junction of the $\mathrm{p}$ and $\mathrm{n}$ type semiconductor, then the excited photons from the solar light jumps out the electrons from their orbits and thus make them to move freely, thus producing flow of electrons that in turn generates voltage across it and hence converts to electrical energy. The process is shown in figure 1.

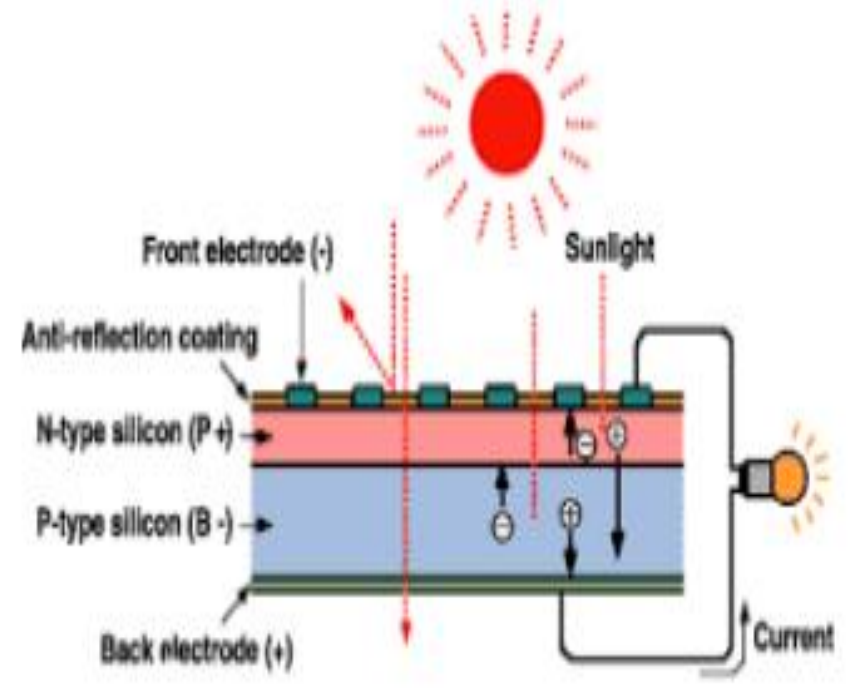

Fig, 1: Photovoltaic Effect

\section{THE SOLAR TREE}

The solar tree is the mixing of the present technology with the new design ideas, both of them are mixed together in an efficient way to build a high tech device with perfect design. The solar tree is used for using solar energy as a means for producing electrical energy [7][8]. The solar tree uses multiple solar panels attached to it in shape of actual tree [9]. The panels are mounted in tall heighted tower shape. The figure 2 illustrates the solar tree. 


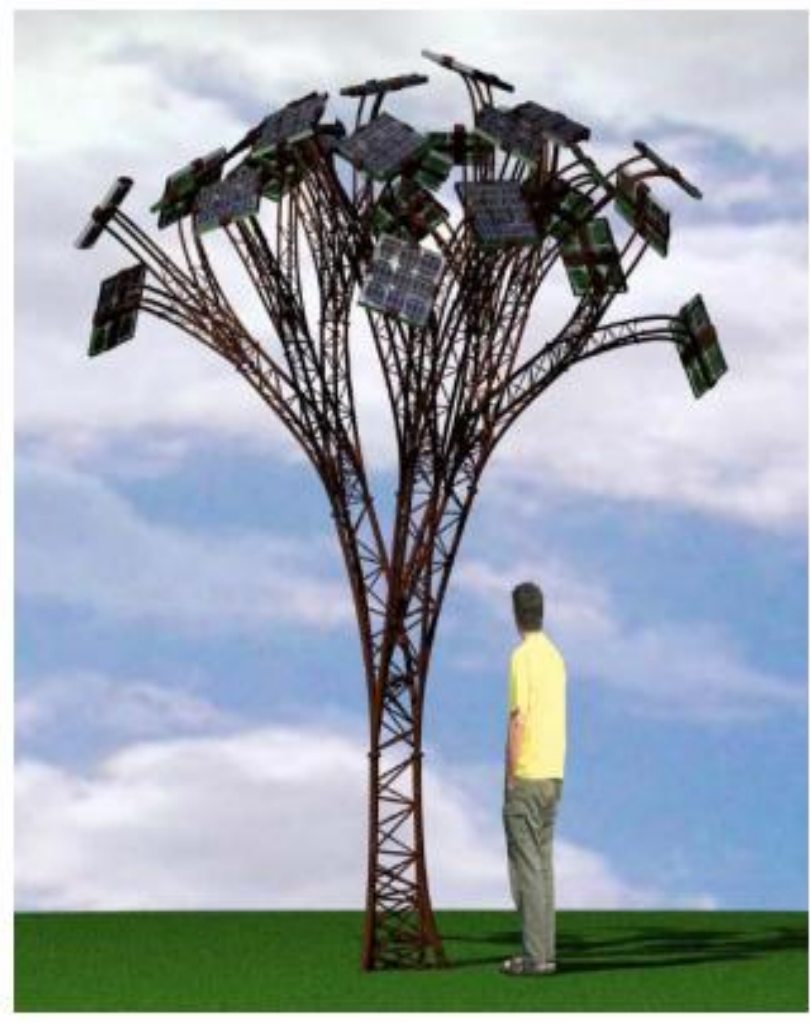

Fig. 2: Design model of solar tree

\section{MAIN COMPONENETS USED IN THE SOLAR TREE \& RESULTS}

1. Multiple solar panels

2. Strong metal tower

3. Multiple lights

4. Battery packs

5. Metallic stem and branches for connecting altogether

\section{Multiple Solar Panels:}

There are multiple solar panels used in the solar tree for harnessing maximum power output from the solar energy. The solar panels are mounted in different directions to increase the surface area in order to capture more sunlight.

\section{Strong Metal Tower:}

The metallic tower provides structural integrity to the solar tree to build, and thus make the solar tree to withstand in any climatic condition.

\section{Multiple lights:}

There are various LED's lights that are attached to the solar tree for using the electrical energy from the solar tree to convert it into light, thus shining every corner around the solar tree with light.

\section{Battery Packs:}

Battery packs are used to store the generated electrical energy from the solar panels and then store it in the form of chemical energy for further use in the future. The stored chemical energy is then converted to electrical energy upon uses.

Metallic stem and branches:
The metallic stem and branches are used for supporting the mounted solar panels, lights and battery packs. The metallic stem and branches provides different positions and angles to the solar panels for capturing solar energy.

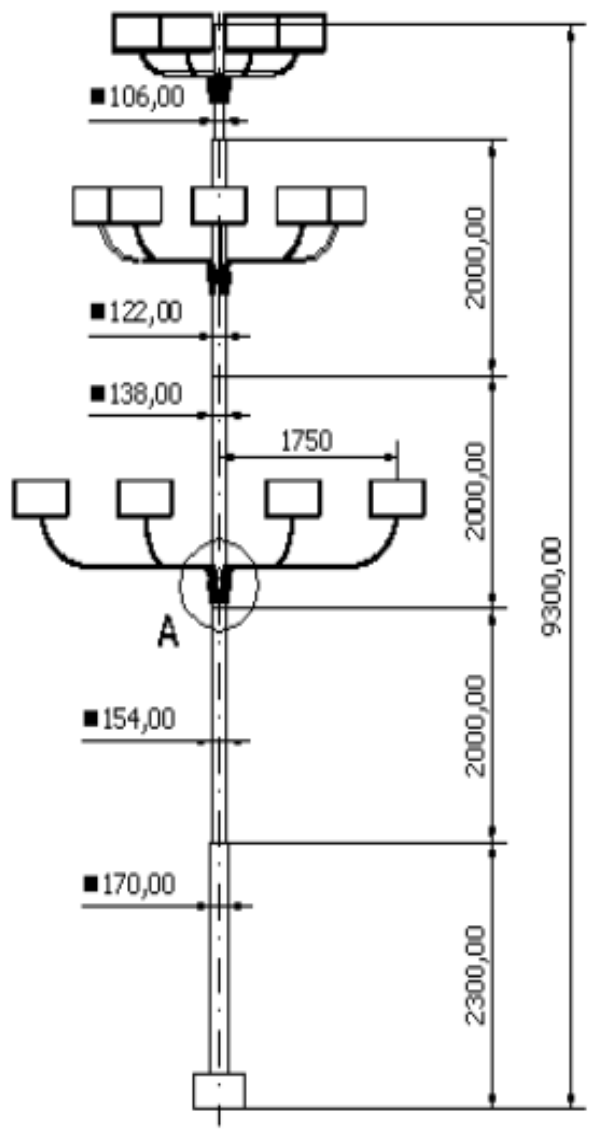

Figure 2: a solar tree

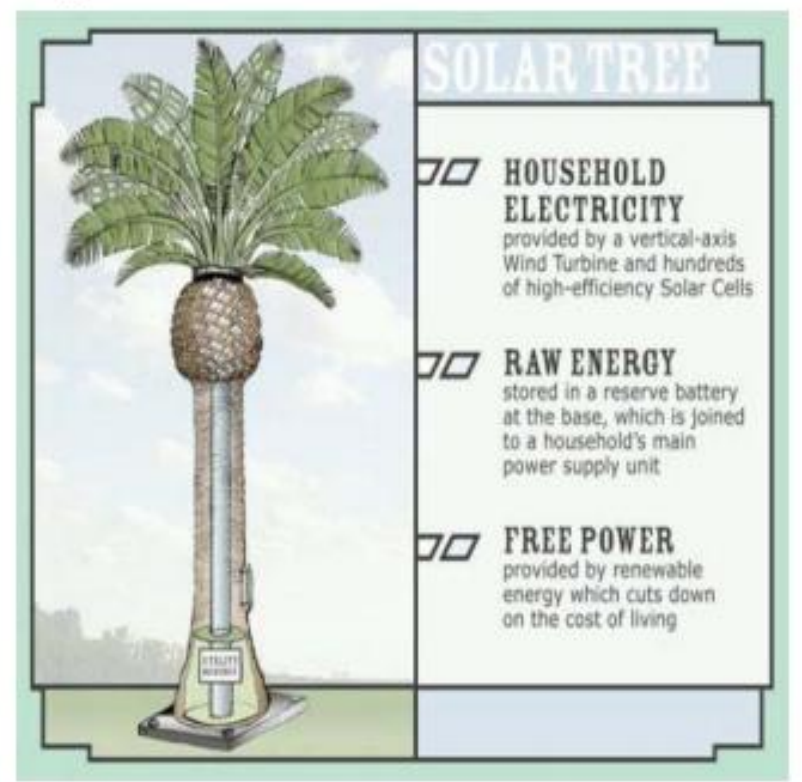

Figure 3: Applications of solar tree

There are multiple applications of the solar tree, one of them is to use it for household electricity, second one is

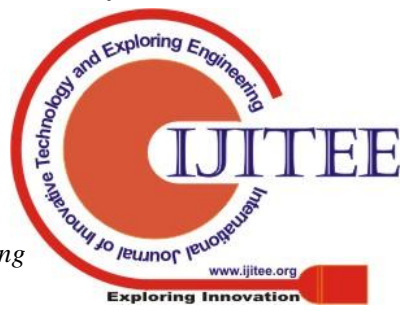


using it as a raw energy and third one is the free power that is being produced from the solar tree by converting solar energy into electrical energy as shown in figure 3.

The output from the solar tree is far better than the other conventional methods that are used for converting solar energy into electrical energy. The energy generated in the month of March is shown in the figure 4, the figure shows the power output from both solar tree and the conventional

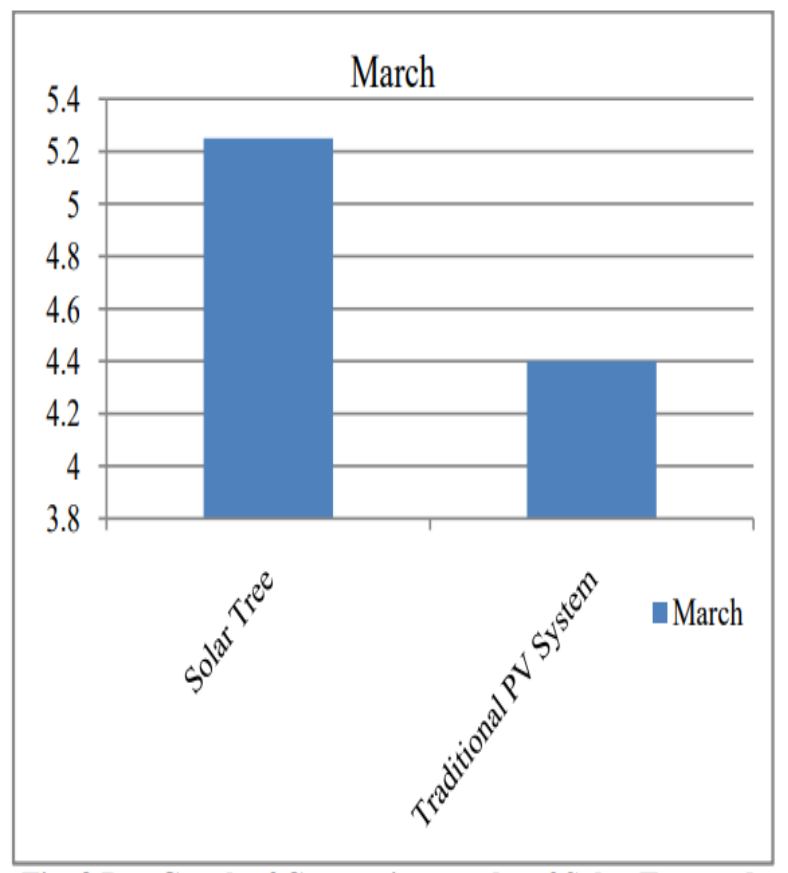

Figure 4: Bar Graph showing solar tree vs conventional setup output

Main advantages of solar tree is that it does not require any large land for energy production. And this system can be used anywhere from a road side to any island with no electrical power grid

\section{CONCLUSION}

Solar trees are the solution to the scarcity of the land, the solar tree can be built in any place and can be installed in any place in all over the world, since sun light is reachable to almost every corner of the earth, there is no place in which the solar tree cannot generate electrical power. And the most important aspect of the solar tree is that it requires very less space to install, there is no need for vast land to install the solar panels that generates same amount of electrical power. The solar tree only takes $1 \%$ of the total land that is required by the conventional methods. There is no cut off of electrical power by the solar tree. This is possible to generate enough electrical power on very less space of land to supply power to the whole world.

\section{REFERENCES}

1. Virginia Polytechnic Institute and State University, "Installation under way for university's first major solar panel system | News | Virginia Tech," Virginia Tech News, 2012.

2. A. Sahay, V. K. Sethi, A. C. Tiwari, and M. Pandey, "A review of solar photovoltaic panel cooling systems with special reference to Ground coupled central panel cooling system (GC-CPCS)," Renewable and Sustainable Energy Reviews. 2015.
3. F. Hyder, K. Sudhakar, and R. Mamat, "Solar PV tree design: A review," Renewable and Sustainable Energy Reviews. 2018.

4. S. Dey, M. K. Lakshmanan, and B. Pesala, "Optimal solar tree design for increased flexibility in seasonal energy extraction," Renew. Energy, 2018.

5. R. and C. of D. S. E. Technologies, "Review and Comparison of Different Solar Energy Technologies," GENI, 2012.

6. B. Parida, S. Iniyan, and R. Goic, "A review of solar photovoltaic technologies," Renewable and Sustainable Energy Reviews. 2011.

7. International Renewable Energy Agency (IRENA), Renewable Power Generation Costs in 2017. 2018.

8. S. Energy et al., "Units and symbols in Solar Energy," Sol. Energy, 2002.

9. W. Cao et al., "'Solar tree': Exploring new form factors of organic solar cells," Renew. Energy, 2014 